\title{
Life Transition Process Effects on Depressive Symptoms in Parents of Children with Autism Spectrum Disorder
}

\author{
Sun Woo Hong ${ }^{1}$, JinShil Kim², Ae Ran Lee ${ }^{3}$, Jeong Sil Choi ${ }^{2}$ \\ ${ }^{1}$ Department of Emergency Medical Services, Daejeon University, Daejeon; ${ }^{2}$ College of Nursing, Gachon University, Incheon; \\ ${ }^{3}$ Department of Nursing, Wonkwang Health Science University, Iksan, Korea
}

Purpose: The purpose of this study is to examine the association between each phase of the Life Transition Process (LTP) and depressive symptoms among parents of children with Autism Spectrum Disorder (ASD). Methods: Using a cross-sectional study design, data pertaining to LTP and depressive symptoms were collected from 285 parents of children with ASD (101 fathers and 184 mothers). Participants were recruited through the Autism Society of Korea and a counseling center for families of children with ASD. Results: Using a cut-off point of 5 or higher on the Beck Depression Inventory-Short Form, more than half of the parents (53.4\%) were deemed depressed; these parents experienced moderate (27.4\%) to severe (11.6\%) levels of depressive symptoms. A hierarchical multiple regression using the socio-demographic characteristics of children and parents and each phase of the LTP as predictors, found that lower income $(\beta=-.14, p=.007)$ and greater scores for the wandering phase $(\beta=.59, p<.001)$ were significant predictors of greater levels of depressive symptoms. Conclusion: These findings confirm the association between LTP and depressive symptoms for parents of children with ASD, who were found to have a greater risk of depressive symptoms during wandering phase.

Key words: Autism spectrum disorder, Depression, Parent, Life

\section{Corresponding author Jeong Sil Choi \\ https://orcid.org/0000-0002-9316-0171}

College of Nursing, Gachon University,

191 Hambakmoe-ro, Yeonsu-dong, Yeonsu-gu, Incheon 21936, Korea

TEL +82-32-820-4211 FAX +82-32-820-4201

E-MAIL jschoi408@empas.com

*This study was supported by the research fund of the Daejeon University in 2014.

Received Jun 15, 2018 Revised Jul 3, 2018 Accepted Jul 4, 2018
(2) This is an Open Access article distributed under the terms of the Creative Commons Attribution NonCommercial License (http://creativecommons.org/licenses/by-nc/4.0/) which permits unrestricted noncommercial use, distribution, and reproduction in any medium, provided the original work is properly cited.

\section{INTRODUCTION}

Children with Autism Spectrum Disorder (ASD) have broad levels of impairment in social interaction and communication, as well as behavioral problems, such as repetitive and aggressive or self-injurious behaviors. Such behavioral problems of children with ASD are often accompanied by physical, emotional, and financial burdens to their parents and increased stress in their marital relationships [1,2].

Particularly, unmet parental emotional needs can lead to clinical depression or mental illness in parents [1]. Maternal depression showed significant associations with parenting, whereas mothers with lower levels of depression showed better parenting and their parenting was enhanced with greater social support and maternal health [3]. Mothers' depression were associated with their children's adverse outcomes [4,5]. For example, problematic internalizing and externalizing behaviors of autistic children more often occurred in the relationships to their exposure to chronic maternal depression [4, 5]. For young children displaying developmental delays, those who might be eligible for early intervention services, maternal depression often prevented or delayed children from receiv- 
ing such services [6]. In addition, the amount of stress perceived by parents of children with ASD also increased parental depressive symptoms and decreased parents' psychological well-being [7].

Parental reactions or coping patterns may vary depending on the growth of the disabled children across the developmental process [8]. Altiere and von Kluge [9] reported that parents of children with ASD perceived a child's diagnosis of autism as being a life-altering event, and experienced five different challenges: development, questioning, devastation, solutions, and growth in the process of raising a child with ASD. Meleis et al. [10] further suggested that health and illness challenges involve a process of transition that also increases parents' vulnerability to poor health. In this regard, a series of studies by Lee et al. [11-14] investigated how mothers of children with autism experienced life transitions, and suggested differentiated support and care at each stage. Mothers who have children with ASD experienced five phases of the Life Transition Process (LTP): denying, wandering, devoting, mind controlling, and accepting [11]. These findings comprised the basis for developing and revising the Life Transition Scale (LTS) for parents who have children with autism, identifying four phases: denying, wandering, despairing, and accepting. In the denying phase, mothers do not believe the diagnosis and symptoms and therefore avoid them. In the wandering phase, mothers experience high levels of stress, guilt, and self-blame. The despair phase is the stage of exhaustion, whereas in the accepting phase mothers reorganize their lives as mothers who are rearing children with ASD [12,13]. Notably, there was no difference in the despair or acceptance phases between mothers and fathers [14].

Although the series of studies by Lee et al. [11-14] shed light on how parents of children with autism experienced life transitions, there is little empirical evidence for how such transitional experiences influence parental psychological functioning or suggestions regarding the support and care needed for each phase of the LTP. Specifically, parents of children with ASD have a high risk of depression, yet few studies have addressed whether their symptoms change during the transitional process of caring for children with ASD.

Therefore, this study was conducted to identify which factors among the socio-demographic characteristics and LTP were influencing on depressive symptoms in parents of children with ASD.

\section{METHODS}

\section{Study Design}

This study was a descriptive cross-sectional survey.

\section{Participants and Procedures}

Participants were recruited through the Autism Society of Korea and a counseling center for families of children with ASD from January to June 2016. After obtaining approval from six regional branches of the Association and a counseling center located in Seoul, Deajeon, Gyeonggi, Gangwon, Jeonbuk, and Gyeongnam Province, teachers and counselors distributed 350 questionnaire booklets, with a stamped envelope for their return, to parents of children with ASD. The subjects of this study were enrollees of the Autism Society of Korea and families of children with ASD. The diagnosis and the level of disability of the ASD children were determined by a pediatric psychiatrist. Other inclusion criteria were parents of children with ASD who obtained full financial support and there were no age-restrictions for the children. The envelope also contained instruction guidelines for completing the questionnaires, an informed consent form, and a token of appreciation. The required sample size for this study was estimated using $G^{*}$ Power 3.1.5 [15]. When input into a linear multiple regression analysis using $\alpha=.05$, medium effect size $\mathrm{f}^{2}=.15$, power $=.95$, and number of predictors $=13$, the minimum sample size for this study was 189 . Considering the potential for a high drop-out rate $[13,14]$, a sample size of 350 was used for this study. Surprisingly, 312 questionnaires were returned (response rate $=89.1 \%$ ), with 285 ultimately selected for use due to the exclusion of 27 questionnaires that had incomplete responses.

\section{Ethical Considerations}

Approval for conducting this study was obtained from the Institutional Review Board of W University (WKIRB-201512SB-053).

\section{Measurements}

\section{1) Beck Depression Inventory-Short Form}

The 13-item Beck Depression Inventory-Short Form (BDI-SF) used in this study is a measure of depressive symptoms that was developed as a rapid screening tool in medical clinics [16, 17]. Using a four-point Likert-type scale (not true $=0$ to completely or always true $=3$ ), scores ranged from 0 to 39 , with higher scores indicating severe depressive symptoms. The levels of depressive symptoms were determined by the following cutoff points: $0 \sim 4$ for none or minimal, $5 \sim 7$ for mild, $8 \sim 15$ for moderate, and 16 or higher for severe depression. In the previous study, the internal consistency reliability was .83 for the BDI-SF [17]. In the current study, the $\alpha$ coefficient was 92 . 


\section{2) Life Transition Scale}

The Life Transition Scale (LTS) is a parent-report scale that assesses the LTP of parents who have children with ASD [13]. Parents are instructed to respond with their current feelings regarding life using a four-point Likert-type scale (not true $=1$ to completely or always true $=4$ ). This scale consists of 24 items and is divided into 4 subscales: denying (6 items), wandering (8 items), despairing (4 items), and accepting (6 items) phases. For each phase, scores are summed and averaged, ranging from 1 4, which enables comparisons of life transition feelings across the phases. Psychometric properties were previously documented using a confirmatory factor analysis, with acceptable internal consistency for each of 4 subscales. In the previous study, the $\alpha$ coefficient of the total scale was .83 , and denying .86 , wandering .90 , despairing .77 , accepting .85 [13]. In the current study, the $\alpha$ coefficient of the total scale was .82, and .86, .89, .78, and .85 for each of the denying, wandering, despairing, and accepting phase subscales, respectively.

\section{3) Demographic questionnaire}

Parents were asked to indicate their age, gender, education, employment, religion, and household income, as well as their child's age, gender, and disability level [12-14,18].

\section{Data Analysis}

The data were analyzed using SPSS/WIN 23.0. Prior to the statistical analysis, normality or multicollinearity assumptions for the main variables were verified using a KolmogorovSmirnov test. Descriptive statistics were calculated to describe the sample, which included socio-demographic characteristics and parental depression. Differences in depression level by socio-demographic characteristics were analyzed using ttests and one-way analysis of variance with a Scheffé post-hoc test for group comparisons. To examine the relationship between the LTP and depressive symptoms, Pearson correlation coefficients were computed; and a hierarchical multiple regression analysis was conducted to identify factors influencing for depressive symptoms in parents, in which children's general characteristics, including age, gender, and disability level, were entered in the first step, followed by parents' characteristics (age, gender, education, employment, religion, and household income) in the second step, with the parents' LTP being the final component added [12-14,19].

\section{RESULTS}

\section{Participants' Socio-demographic Characteristics}

The mean age of the children was 11.92 years old $(\mathrm{SD}=7.93)$.
The children comprised 100 preschoolers ( $\leq 6$ years old) ( 35.1 $\%), 65$ elementary school students (7 12 years old) (22.8\%), 59 adolescents (13 18 years old) (20.7\%), and 61 adults ( $\geq 19$ years old) $(21.4 \%)$. There were 187 male (65.6\%). The disability levels of the children with ASD were as follows: 97 (34.0\%) in the 1st level, 72 (25.3\%) in the 2nd level, and 116 (40.7\%) in the 3rd level or higher.

Participants included 101 fathers (35.4\%) and 184 mothers (64.6\%). The mean age of participants was 42.27 years old (SD= 8.61). By age category, 121 (42.5\%) were 39 years old or younger, $104(36.5 \%)$ were $40 \sim 49$ years old, and $60(21.1 \%)$ were 50 years or older. Education levels were as follows: 129 (45.3\%) participants with high school or lower, 150 (54.7\%) with college or higher, and missing data is not included in the values. Household income levels among participants were as follows: 111 (42.5\%) earned 300 million won per month or higher, 83 (29.1\%) earned 200 million won per month or less, and missing data is not included in the values (Table 1).

\section{Differences in Parents' Depressive Symptoms according to Socio-demographic Characteristics}

There were statistically significant differences in parent's depressive symptoms according to their child's disability level $(\mathrm{F}=4.35, p=.014)$, the parent's age $(\mathrm{F}=3.00, p=.051)$, the parent's gender $(\mathrm{t}=2.53, p=.012)$, employment status $(\mathrm{t}=2.57, p=$ $.011)$, and household income $(\mathrm{F}=6.32, p=.002)$. Depressive symptoms for parents who were 39 years and younger appeared to be higher than for those who were 50 years and older, and mothers reported higher levels of depressive symptoms than did fathers. A lack of employment and lower household income were also associated with higher depressive symptom scores, as shown in Table 1.

\section{Characteristics of Depressive Symptoms in Parents of Children with ASD}

The mean BDI-SF depressive symptom score for parents was $7.09(\mathrm{SD}=6.84)$. Based on the cutoffs, $53.4 \%$ of the parents were deemed depressed: $14.4 \%$ mild, $27.4 \%$ moderate, and $11.6 \%$ with severe depressive symptoms, as shown in Table 2.

\section{Correlations between Parents' Depressive Symptoms and the LTP}

Parents' depressive symptoms were strongly correlated with the LTP phases: denying phase $(\mathrm{r}=.62, p<.001)$, wandering phase $(\mathrm{r}=.74, p<.001)$, and despairing phase $(\mathrm{r}=.47, p<.001)$. Parental depressive symptoms were negatively correlated with the accepting phase $(r=-.27, p<.001)$ as shown in Table 3. 
Table 1. Socio-demographic Characteristics and Demographic Differences in Depressive Symptoms of Parents of Children with Autism Spectrum Disorder

$(N=285)$

\begin{tabular}{|c|c|c|c|c|c|c|}
\hline Variables & & Categories & $\mathrm{n}(\%)$ or $\mathrm{M} \pm \mathrm{SD}$ & Range & $\mathrm{M} \pm \mathrm{SD}$ & $\begin{array}{l}\text { t or F }(p) \\
\text { Scheffé }\end{array}$ \\
\hline \multirow[t]{3}{*}{ Child } & Age (year) & $\begin{array}{l}\leq 6 \\
7 \sim 12 \\
13 \sim 18 \\
\geq 19\end{array}$ & $\begin{array}{r}100(35.1) \\
65(22.8) \\
59(20.7) \\
61(21.4) \\
11.92 \pm 7.93\end{array}$ & $2 \sim 31$ & $\begin{array}{l}8.22 \pm 6.59 \\
7.09 \pm 6.52 \\
6.30 \pm 6.24 \\
6.01 \pm 7.92\end{array}$ & $\begin{array}{l}1.68 \\
(.171)\end{array}$ \\
\hline & Gender & $\begin{array}{l}\text { Male } \\
\text { Female }\end{array}$ & $\begin{array}{r}187(65.6) \\
98(34.4)\end{array}$ & & $\begin{array}{l}6.71 \pm 6.19 \\
7.82 \pm 7.91\end{array}$ & $\begin{array}{c}1.30 \\
(.192)\end{array}$ \\
\hline & Disability level & 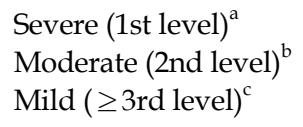 & $\begin{array}{r}97(34.0) \\
72(25.3) \\
116(40.7)\end{array}$ & & $\begin{array}{l}6.31 \pm 6.78 \\
5.86 \pm 6.26 \\
8.51 \pm 7.06\end{array}$ & $\begin{array}{l}4.35 \\
(.014) \\
b<c\end{array}$ \\
\hline \multirow[t]{6}{*}{ Parent } & Age (year) & $\begin{array}{l}\leq 39^{\mathrm{a}} \\
40 \sim 49^{\mathrm{b}} \\
\geq 50^{\mathrm{c}}\end{array}$ & $\begin{array}{c}121(42.5) \\
104(36.5) \\
60(21.0) \\
42.27 \pm 8.61\end{array}$ & $26 \sim 68$ & $\begin{array}{l}8.06 \pm 6.46 \\
6.90 \pm 7.24 \\
5.46 \pm 6.62\end{array}$ & $\begin{array}{l}3.00 \\
(.051) \\
\mathrm{c}<\mathrm{a}\end{array}$ \\
\hline & Gender & $\begin{array}{l}\text { Father } \\
\text { Mother }\end{array}$ & $\begin{array}{l}101(35.4) \\
184(64.6)\end{array}$ & & $\begin{array}{l}5.72 \pm 6.67 \\
7.84 \pm 6.83\end{array}$ & $\begin{array}{c}2.53 \\
(.012)\end{array}$ \\
\hline & Education* & $\begin{array}{l}\leq \text { High school } \\
\geq \text { College }\end{array}$ & $\begin{array}{l}129(45.3) \\
150(54.7)\end{array}$ & & $\begin{array}{l}6.21 \pm 5.70 \\
6.71 \pm 6.41\end{array}$ & $\begin{array}{c}1.70 \\
(.089)\end{array}$ \\
\hline & Employment* & $\begin{array}{l}\text { No } \\
\text { Yes }\end{array}$ & $\begin{array}{l}143(50.2) \\
130(49.8)\end{array}$ & & $\begin{array}{l}8.38 \pm 6.98 \\
5.42 \pm 6.06\end{array}$ & $\begin{array}{c}2.57 \\
(.011)\end{array}$ \\
\hline & Religion* & $\begin{array}{l}\text { No } \\
\text { Yes }\end{array}$ & $\begin{array}{l}144(50.5) \\
140(49.5)\end{array}$ & & $\begin{array}{l}7.88 \pm 7.16 \\
6.27 \pm 6.44\end{array}$ & $\begin{array}{c}0.99 \\
(.319)\end{array}$ \\
\hline & $\begin{array}{l}\text { Household income* } \\
\text { (10,000 won) }\end{array}$ & $\begin{array}{l}<200^{\mathrm{a}} \\
200 \sim 299^{\mathrm{b}} \\
\geq 300^{\mathrm{c}}\end{array}$ & $\begin{array}{r}83(29.1) \\
81(28.4) \\
111(42.5)\end{array}$ & & $\begin{array}{l}9.38 \pm 8.19 \\
6.65 \pm 5.75 \\
5.99 \pm 6.30\end{array}$ & $\begin{array}{c}6.32 \\
(.002) \\
\mathrm{b}, \mathrm{c}<\mathrm{a}\end{array}$ \\
\hline
\end{tabular}

*Missing data is not included in the values.

Table 2. Levels of Depressive Symptoms of Parents of Children with Autism Spectrum Disorder $(N=285)$

\begin{tabular}{lcc}
\hline Depressive symptom level* & $\mathrm{n}(\%)$ & $\mathrm{M} \pm \mathrm{SD}$ \\
\hline None/minimal & $133(46.6)$ & $7.09 \pm 6.84$ \\
Mild & $41(14.4)$ & \\
Moderate & $78(27.4)$ & \\
Severe & $33(11.6)$ & \\
\hline
\end{tabular}

*The following cut-off points for the Beck Depression Inventory-Short Form were used to classify depressive symptom levels: none $=0 \sim 4$, mild $=5 \sim 7$, moderate $=8 \sim 15$, and severe $=16$ or higher.

\section{Factors Influencing Depressive Symptoms in Parents of Children with ASD}

A hierarchical multiple regression analysis was conducted to identify factors influencing depression in parents of children with ASD. In the first step, children's socio-demographic characteristics explained only $2 \%$ of the depression in parents
Table 3. Correlations between Parental Depressive Symptoms and Life Transition Process Phase

$(N=285)$

\begin{tabular}{lcc}
\hline \multirow{2}{*}{ Life transition process } & \multicolumn{2}{c}{ Depressive symptoms } \\
\cline { 2 - 3 } & $\mathrm{r}$ & $p$ \\
\hline Denying phase & .62 & $<.001$ \\
Wandering phase & .74 & $<.001$ \\
Despairing phase & .47 & $<.001$ \\
Accepting phase & -.27 & $<.001$
\end{tabular}

(Model I, F=2.96, $p=.033$ ), and there was no significant influencing factor.

In the second step, when adding the socio-demographic characteristics of the parents, the explanatory power for depressive symptoms increased to $12 \%$ (Model II, F=4.70, $p<$ .001). Parent's employment $(\beta=-.14, t=1.99, p=.048)$ and household income $(\beta=-.21, t=2.72, p=.003)$ were significant influencing factors. 
Table 4. Risk Factors for Depression in Parents of Children with Autism Spectrum Disorder

$(N=285)$

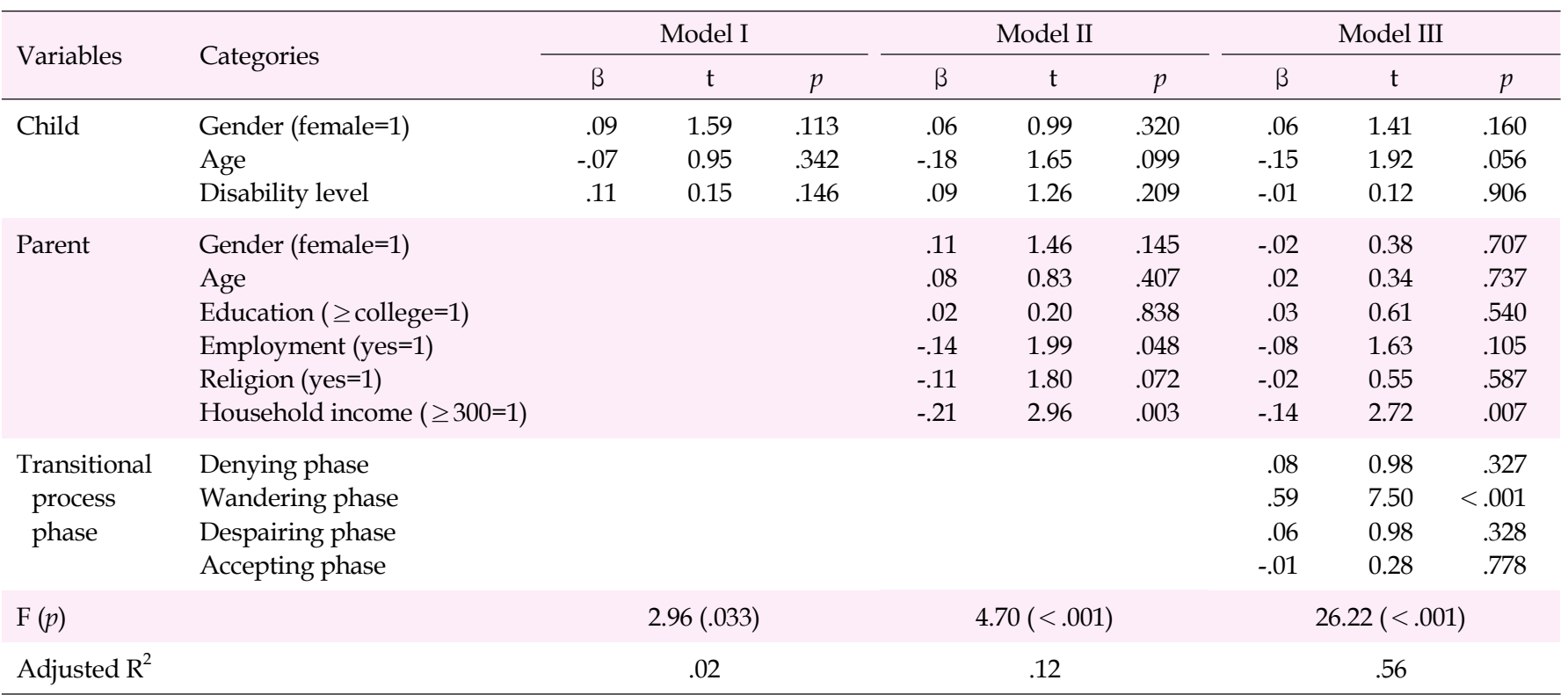

Finally, when the LTP was added, the overall explanatory power increased to $56 \%$ (Model III, $\mathrm{F}=26.22, p<.001$ ). Overall, household income $(\beta=-.14, \mathrm{t}=2.72, p=.007)$ and being in the wandering phase $(\beta=.59, \mathrm{t}=7.50, p<.001)$ were found to be significant factors influencing depression in parents, as shown in Table 4

\section{DISCUSSION}

Parents of children with ASD are at higher risk of depression and more likely to need professional help [20-25]. Parents who have children with ASD experience LTP [11-14].

In this study, the mean parental depression score was 7.09 \pm 6.84 and the levels of depressive symptoms showed that $53.4 \%$ of parents experienced mild, moderate, or severe depressive symptoms, with $11.6 \%$ of them experiencing severe depressive symptoms. This is a very high prevalence rate of depressive symptoms, compared to the $28 \%$ of mothers and $29 \%$ of fathers among Korean-American parents of children with ASD who experienced depressive symptoms [24].

In this study, parents' depressive symptoms were strongly associated with the LTP. It is important to note that the denying, wandering, and despairing phases were positively associated with parents' depression, whereas the accepting phase had a negative association. This result is supported by the previous studies in which reported positive coping was associated with lower levels of parental depression [26]; psychological acceptance was also negatively related to the severity of parent mental health problems [27]. In another study, caregivers raising a child with ASD experienced more substantial stress than enrichment; growth and enrichment might also occur in varying degrees [23].

It is difficult to determine the exact timing of the autism diagnosis due to the tendency of the parents to delay initial hospital visits for diagnosis [11]. In addition, it is difficult to report on the exact diagnosis period because of the challenge of recognizing of the child's disability even if the child had a diagnosis [1,2]. When parents initially heard a diagnosis of autism, they felt that their child was doomed to a difficult life with little hope of recovery, but parents struggled to accept their new reality of having a child with autism [11]. Following diagnosis, parents of children with autism underwent a period of readjustment, and gradually parents viewed themselves and their offspring in a positive light [11]. Parents are always concerned for their children's future, such as whether their child will be able to live independently and be accepted by society $[11,28]$. However, as most children with ASD do not live independently even after they grow reaching adulthood, so parents' anxieties, fears, worries, and loneliness could increase [11]. Therefore, it is necessary for professionals to assess the current LTP phase of parents in order to provide differentiated and intensive support programs and to help them move from the wandering phase to the accepting phase.

In the first step of the hierarchical multiple regression analysis in this study, depressive symptoms in parents of children with ASD were not predicted by the children's socio-demographic characteristics. This result was supported by a report that autism severity and children's externalizing behaviors did not directly influence parental psychological distress, which was mediated by parental cognition and socio-econom- 
ic support [22], although many researchers report that child symptom severity has been positively associated with depression $[20,25,28,29]$. In the second step, depressive symptoms in parents of children with ASD were predicted by employment and household income. This relationship between low socio-economic status and depression has been supported by numerous studies $[18,19,29]$. The adverse effects of economic hardship on both mental and physical health and functioning are evident from a young age and persist across a person's lifespan. Moreover, these studies report that the effects of economic disadvantage are cumulative, with the greatest risk of poor mental and physical health seen among those who experience sustained hardship over time. These findings suggest that parents of children with ASD who have a low household income need careful social support because of their high risk of depression.

Finally, in the last step, depressive symptoms in parents of children with ASD was predicted by household income and the wandering phase of LTP.

Depressive symptoms in parents who do not have a job or have a lower household income were higher than for parents who have a job and higher income. Socio-economic support was indicated as being the primary predictor of mental health problems and mediated the relationship between child-related factors and parental psychological distress $[18,22]$. Taking care of children with ASD in daily life is a long journey; therefore, we should consider that the response of parents may vary in accordance with the process of children's growth. Changes in parents' emotional reactions were attributed to LTP by Lee et al [12-14].

In the wandering phase, parents do not accept their children's disabilities and devote their lives to trying to make their children 'normal'[11]. When the age at diagnosis ranged from 3 to 11 years, this particular group of mothers expressed uncertainty about their child's future, though the majority also believed that change was possible [21]. When receiving an autism diagnosis, all parents identified experiencing extreme emotion and described the confusion resulting from their child's behavioral presentation and the subsequent feelings of loss and devastation that occurred [30]. Although parents understood that they could not expect that their child would behave as other 'normal' children, most did not abandon hope that a significant change in their child would occur [11]. Mothers in particular spent a great deal time ensuring their children obtained therapy, such as language, art, and sense therapy, as well as special day-long treatments.

In this situation, as mothers do not have time to care for other family members, the family can gradually become disrupted [12]. Because parents devote their focus on a child with ASD, they can experience serious economic, physical, and emotional stress $[7,11,29]$. This ongoing of conflict can lead to depression and frustration, requiring special care and support to mitigate. Importantly, there is urgent need to screen for the current LTP phase of parents and to intervene to reduce levels of depression and help them to lead a healthier life.

Finally, unlike previous studies [20,25,29], the severity of a child's disability level was not deemed to be a significant predictor of depressive symptoms, this finding may be due to differences in the method of measuring the degree of severity of the disability in each study, and as such it is necessary to further compare factors influencing these factors in a future study.

A limitation of this study was that only parents within a specific region were included. Therefore, further validation of the study findings is warranted, using a representative sample. LTS has limitations in that it shows only each characteristic score, not the process. Therefore, further studies will need to explore the tools used that characterize the process. Despite these limitations, however, the current study has initiated a benchmark for how parents of children with ASD experience LTP and depression. The study also contributes to research in this field by identifying aspects and risk factors for depressive symptoms in parents of children with ASD. In a subsequent study, we propose to compare the characteristics of depressive symptoms, life transitions, and factors that affect depressive symptoms in both the father and mother in consideration of common gender characteristics.

\section{CONCLUSION}

This study examined the effects of LTP on the depressive symptoms of parents of children with ASD. We found that depressive symptoms in parents is common, with more than half experiencing at least mild depressive symptoms, and among those, approximately one in ten suffer from severe depressive symptoms. Such psychological vulnerability increased in conjunction with socio-demographic characteristics, including child's disability level, being younger parents, being a mother, employment status, and being a low income family. Importantly, predicting the severity of depressive symptoms in parents was found to be possible based on the LTP phase, particularly the wandering phase. Such information could be the focus for developing a psychological intervention for parents of children with ASD in order to promote a healthier life by considering the association between LTP and depressive symptoms.

\section{Conflict of interest}

No potential or existing conflict of interest relevant to this article was reported. 


\section{REFERENCES}

1. Estes A, Munson J, Dawson G, Koehler E, Zhou XH, Abbott R. Parenting stress and psychological functioning among mothers of preschool children with autism and developmental delay. Autism. 2009;13(4):375-387. https://doi.org/10.1177/1362361309105658

2. Rivard M, Terroux A, Parent-Boursier C, Mercier C. Determinants of stress in parents of children with autism spectrum disorders. Journal of Autism and Developmental Disorders. 2014;44(7):16091620. https://doi.org/10.1007/s10803-013-2028-z

3. Waylen A, Stewart-Brown S. Factors influencing parenting in early childhood: A prospective longitudinal study focusing on change. Child: Care, Health and Development. 2010;36(2):198-207. https://doi.org/10.1111/j.1365-2214.2009.01037.x

4. Hanington L, Heron J, Stein A, Ramchandani P. Parental depression and child outcomes- is marital conflict the missing link? Child: Care, Health and Development. 2012;38(4):520-529.

https://doi.org/10.1111/j.1365-2214.2011.01270.x

5. Trapolini T, McMahon CA, Ungerer JA. The effect of maternal depression and marital adjustment on young children's internalizing and externalizing behaviour problems. Child: Care, Health and Development. 2007;33(6):794-803. https://doi.org/10.1111/j.1365-2214.2007.00739.x

6. Feinberg E, Donahue S, Bliss R, Silverstein M. Maternal depressive symptoms and participation in early intervention services for young children. Maternal and Child Health Journal. 2012;16(2): 336-345. https://doi.org/10.1007/s10995-010-0715-3

7. Rezendes DL, Scarpa A. Associations between parental anxiety/ depression and child behavior problems related to autism spectrum disorders: The roles of parenting stress and parenting selfefficacy. Autism Research and Treatment. 2011;2011:395190.

https://doi.org/10.1155/2011/395190

8. Wei X, Yu JW. The concurrent and longitudinal effects of child disability types and health on family experiences. Maternal and Child Health Journal. 2012;16(1):100-108.

https://doi.org/10.1007/s10995-010-0711-7

9. Altiere MJ, von Kluge S. Searching for acceptance: Challenges encountered while raising a child with autism. Journal of Intellectual \& Developmental Disability. 2009;34(2):142-152. https://doi.org/10.1080/13668250902845202

10. Meleis AI, Sawyer LM, Im EO, Hilfinger Messias DK, Schumacher $\mathrm{K}$. Experiencing transitions: An emerging middle-range theory. Advanced in Nursing Science. 2000;23(1):12-28.

11. Lee AR, Hong SW, Kim JS, Ju SJ. Life transition of mothers of children with autism. Journal of Korean Academy of Nursing. 2010;40 (6):808-819. https://doi.org/10.4040/jkan.2010.40.6.808

12. Lee AR, Hong SW, Ju SJ. Development of a scale to measure life transition process in parents of children with autism. Journal of Korean Academy of Nursing. 2012;42(6):861-869.

https://doi.org/10.4040/jkan.2012.42.6.861
13. Lee AR, Hong SW, Ju SJ. Construct validity of the life transition scale for parents of children with autism. Journal of Korean Academy of Nursing. 2014;44(5):563-572. https://doi.org/10.4040/jkan.2014.44.5.563

14. Lee AR, Hong SW. Differences in life transition process of parents caring for children with autism: Based on the socio-demographic characteristics. Child Health Nursing Research. 2015;21(4):331-338. https://doi.org/10.4094/chnr.2015.21.4.331

15. Faul F, Erdfelder E, Lang AG, Buchner A. G*Power 3: A flexible statistical power analysis program for the social, behavior, and biomedical sciences. Behavior Research Methods. 2007;39(2):175191.

16. Beck AT, Rial WY, Rickels K. Short form of depression inventory: Cross-validation. Psychological Reports. 1974;34(3):1184-1186.

17. Reynolds WM, Gould JW. A psychometric investigation of the standard and short form Beck Depression Inventory. Journal of Consulting and Clinical Psychology. 1981;49(2):306-307.

18. Al-Oran HM, AL-Sagarat AY. Parenting stress of children with autistic disorder. Open Access Library Journal. 2016;3:e2791. https://doi.org/10.4236/oalib.1102791

19. Jokela M, Keltikangas-Järvinen L. The association between low socioeconomic status and depressive symptoms depends on temperament and personality traits. Personality and Individual Differences. 2011;51(3):3020308. https://doi.org/10.1016/j.paid.2010.05.004

20. Bailey Jr. DB, Golden RN, Roberts J, Ford A. Maternal depression and developmental disability: Research critique. Developmental Disabilities Research Reviews. 2007;13(4):321-329. https://doi.org/10.1002/mrdd.20172

21. Dale E, Jahoda A, Knott F. Mothers' attributions following their child's diagnosis of autistic spectrum disorder: Exploring links with maternal levels of stress, depression and expectations about their child's future. Autism. 2006;10(5):463-479. https://doi.org/10.1177/1362361306066600

22. Falk NH, Norris K, Quinn MG. The factors predicting stress, anxiety and depression in the parents of children with autism. Journal of Autism and Developmental Disorders. 2014;44(12):3185-3203. https://doi.org/10.1007/s10803-014-2189-4

23. Phelps KW, McCammon SL, Wuensch KL, Golden JA. Enrichment, stress and growth from parenting an individual with an autism spectrum disorder. Journal of Intellectual \& Developmental Disability. 2009;34(2):133-141. https://doi.org/10.1080/13668250902845236

24. Kim E. Intergenerational acculturation conflict and Korean American parents' depression symptoms. Issues in Mental Health Nursing. 2011;32(11):687-695. https://doi.org/10.3109/01612840.2011.597017

25. Davis NO, Carter AS. Parenting stress in mothers and fathers of toddlers with autism spectrum disorders: Associations with child characteristics. Journal of Autism and Developmental Disorders. 
2008;38(7):1278-1291. https://doi.org/10.1007/s10803-007-0512-z

26. Hastings RP, Kovshoff H, Brown T, Ward NJ, Espinosa FD, Remington $\mathrm{B}$. Coping strategies in mothers and fathers of preschool and school-age children with autism. Autism. 2005;9(4):337-391. https://doi.org/10.1177/1362361305056078

27. Weiss JA, Cappadocia MC, MacMullin JA, Viecili M, Lunsky Y. The impact of child problem behaviors of children with ASD on parent mental health: The mediating role of acceptance and empowerment. Autism. 2012;16(3):261-274. https://doi.org/10.1177/1362361311422708

28. Donaldson SO, Elder JH, Self EH, Christie MB. Fathers' perceptions of their roles during in-home training for children with au- tism. Journal of Child and Adolescent Psychiatric Nursing. 2011; 24(4):200-207. https://doi.org/10.1111/j.1744-6171.2011.00300.x

29. Ingersoll B, Hambrick DZ. The relationship between the broader autism phenotype, child severity, and stress and depression in parents of children with autism spectrum disorders. Research in Autism Spectrum Disorders. 2011;5(1):337-344.

https://doi.org/10.1016/j.rasd.2010.04.017

30. Lassetter JH, Mandleco BL, Roper SO. Family photographs: Expressions of parents raising children with disabilities. Qualitative Health Research. 2007;17(4):456-467.

https://doi.org/10.1177/1049732306298804 